\title{
Mines, métallurgie et forêt dans les Pyrénées ariégeoises de l'
}

\section{(apenEdition}

\section{Journals}

Édition électronique

URL : http://journals.openedition.org/adlfi/10623

ISSN : 2114-0502

Éditeur

Ministère de la culture

Référence électronique

"Mines, métallurgie et forêt dans les Pyrénées ariégeoises de l' », ADLFI. Archéologie de la FranceInformations [En ligne], Midi-Pyrénées, mis en ligne le 01 mars 1997, consulté le 01 mai 2019. URL http://journals.openedition.org/adlfi/10623

Ce document a été généré automatiquement le 1 mai 2019.

(C) Ministère de la Culture et de la Communication, CNRS 


\title{
Mines, métallurgie et forêt dans les Pyrénées ariégeoises de l'
}

\author{
Identifiant de l'opération archéologique : \\ Date de l'opération : 1988 - 1990 (PC) ; 1991 (PR) \\ Inventeur(s) : Dubois Claude
}

1 Le projet collectif de recherche «Mines, métallurgie et forêts dans les Pyrénées ariégeoises de l'Antiquité au Moyen Âge», avait pour objectif de reconstituer le lien diachronique,société/mines et métallurgie/forêts, dans ses implications tant historiques et technologiques que paléo-écologiques. Terrain favorable à ce type d'enquête,cet axe de recherche a surtout privilégié les Pyrénées ariégeoises,avec leurs principales richesses naturelles, les minerais et les forêts,en prenant pour base les exploitations minières, les gisements métallurgiques,la reconnaissance et l'étude des sites d'habitats liés à ces activités économiques et les forêts elles-mêmes.

2 Il nous a donc paru intéressant d'intégrer les résultats acquis à l'issue du programme de recherche CNRS consacré à «La forêt charbonnée. Histoire des forêts et impact de la métallurgie dans les Pyrénées ariégeoises au cours des deux millénaires », et qui portent sur un secteur géographique pratiquement identique (vallées de l'Aston et du Vicdessos en Haute-Ariège, la vallée d'Aulus-les-Bains en Couserans, le front nord du massif de l'Arize et la dépression pré-pyrénéenne).

3 La mise en conjonction de ces données (pour le programme de recherche CNRS) permet ainsi de réaliser un panorama complet de l'état actuel des connaissances: les sources écrites médiévales ont par exemple servi de support d'évaluation des potentialités (Catherine Verna), ce qui a permis d'apprendre que la mine de fer de Rivérenert était déjà en exploitation au XIV ${ }^{\mathrm{e}} \mathrm{s}$. et qu'à cette même époque, il existait dans la vallée de l'Aston un énorme potentiel sidérurgique utilisant la force motrice de l'eau, pour le profit du comte de Foix. D'autres textes précisent en outre que des mines de plomb et d'argent sont en activité au XIVe $s$. dans les vallées d'Aulus et d'Ustouet qu'elles ont été à l'origine d'une situation conflictuelle entre le vicomte de Couserans, le comte de Foix et le roi de France. 
Conjointement, l'analyse physico-chimique des produits résiduels de l'activité métallurgique du fer dans l'Antiquité a été menée par Catherine Jarrier (dans le cadre d'un doctorat de troisième cycle) sur des scories coulées provenant des sites de La Bastide-de-Sérou, Lercoulet Rivérenert. Les analyses chimiques effectuées au CRPG (CNRS, Nancy), indiquent une forte teneur en oxyde de fer,de $65,90 \%$ à $76,64 \%$, qui implique une consommation importante de minerai lors des opérations métallurgiques. Par ailleurs, les faibles quantités de potasse $(0,96 \%)$ et de calcium $(2,82 \%)$ montrent que les fondants ont peu, ou pas, été utilisés. Enfin, ces travaux nous renseignent sur la formation de ces scories coulées qui se situeraient entre $1150^{\circ} \mathrm{C}$ et $1250^{\circ} \mathrm{C}$.

Le programme sur la forêt charbonnée (CNRS) repose en grande partie sur des études anthracologiques, mais aussi sur des sondages archéologiques réalisés sur des charbonnières, des zones d'extraction et de traitement de minerai au travers de la forêt actuelle qui couvre plus du tiers du département de l'Ariège. Depuis l'Antiquité, cette région montagneuse a fait l'objet de très nombreuses exploitations minières et métallurgiques qui se sont appuyées sur l'utilisation abondante du bois comme combustible. De multiples aires de charbonnage plus ou moins aménagées, des crassiers et quelques mines ouvertes selon la technique $\mathrm{du}$ feu, recèlent des charbons de bois résiduels qui sont autant de témoins de l'utilisation de la forêt. En l'absence de mobilier archéologique des prélèvements de charbons de bois ont été réalisés en vue d'études anthracologiques et de datation au ${ }^{14} \mathrm{C}$.

6 Trois charbonnières, implantées au-dessus des limites actuelles de la forêt,ont été sondées en 1989. Deux sont situées dans la commune d'Aston, Guixel $(1790 \mathrm{~m})$ et Fontargente $(1970 \mathrm{~m})$, la troisième à Auzat, au Pla Nouzère $(1715 \mathrm{~m})$. Aucun mobilier archéologique n'a été mis au jour et seule l'analyse anthracologique permet d'utiles observations puisque nous savons maintenant que le pin était prédominant.

7 Pour compléter l'information, d'autres prélèvements ont été effectués sur les lieux d'utilisation du bois comme combustible, aussi bien dans les ateliers métallurgiques que dans les mines datées de l'Antiquité.

\section{INDEX}

Index chronologique : Deuxième âge du Fer, Empire romain, Moyen Âge operation Projet collectif de recherche (PCR), Prospection (PR) 